\title{
Expression and clinical significance of Apollon in renal carcinoma
}

\author{
HONGBO GUO $^{1 *}$, WEIFENG ZHONG ${ }^{2,3 *}$, XIAOHONG WANG ${ }^{4}$, BIN PAN $^{5}$, \\ FENG $\mathrm{LI}^{6}$, KUANG LU ${ }^{7}$, ZEXUAN SU ${ }^{8}$ and SHIQING ZHANG ${ }^{1}$ \\ ${ }^{1}$ Department of Urology, No. 1 People's Hospital, Jining, Shandong 272011; \\ ${ }^{2}$ Graduate School of Southern Medical University, Guangzhou, Guangdong 510515; \\ ${ }^{3}$ Department of Urology, Traditional Chinese Medicine Hospital of Luogang, Guangzhou, Guangdong 510530; \\ ${ }^{4}$ Department of Nephrology, The Third Affiliated Hospital of Southern Medical University; \\ ${ }^{5}$ Department of Urology, The First Affiliated Hospital of Jinan University, Guangzhou, Guangdong 510630; \\ ${ }^{6}$ Department of Urology, The Fourth Affiliated Hospital of Guangzhou Medical University, Guangzhou, Guangdong 511447; \\ ${ }^{7}$ Department of Urology, The Third Affiliated Hospital of Guangzhou Medical University; ${ }^{8}$ Department of Urology, \\ The First Affiliated Hospital of Guangzhou Medical University, Guangzhou, Guangdong 510630, P.R. China
}

Received July 3, 2015; Accepted October 13, 2016

DOI: $10.3892 / \mathrm{ol} .2016 .5349$

\begin{abstract}
Apollon, namely baculoviral inhibitor of apoptosis proteins (IAP) repeat containing 6 , is an unusually large member of the IAP family, and may be important in oncogenesis. The aim of the present study was to assess the association between renal carcinoma (RC) and Apollon expression, and to highlight the link between Apollon expression and the occurrence, development and prognosis of RC. Apollon expression was detected by immunohistochemistry, western blotting and reverse transcription-quantitative polymerase chain reaction in RC tissues, adjacent non-cancerous tissues and paired normal tissues, respectively, in order to analyze the association between Apollon expression and clinicopathological features of RC. Kaplan-Meier survival estimate was used to assess the prognostic significance. It was observed that Apollon expression was higher in carcinoma tissues than in adjacent non-cancerous tissues and normal control tissues at the protein and messenger RNA level $(\mathrm{P}<0.001)$. There was a significant difference in T-stage $(\mathrm{P}=0.006)$, nodal involvement $(\mathrm{P}=0.007)$ and tumor-node-metastasis-stage $(\mathrm{P}=0.035)$ in patients categorized according to different Apollon expression levels. A prognostic significance of Apollon was also identified by the
\end{abstract}

Correspondence to: Dr Shiqing Zhang, Department of Urology, No. 1 People's Hospital, 6 Jiankang Road, Rencheng, Jining, Shandong 272011, P.R. China

E-mail: shiqing_zhang@yeah.net

Dr Zexuan Su, Department of Urology, The First Affiliated Hospital of Guangzhou Medical University, 151 Yanjiangxi Road, Yuexiu, Guangzhou, Guangdong 510630, P.R. China

E-mail: kuangfei222@126.com

*Contributed equally

Key words: renal carcinoma, Apollon, apoptosis, IAPs, prognosis
Kaplan-Meier method. The results of the present study indicate that Apollon expression is associated with the biological characteristics of renal cancer, and is potentially a valuable predictor and novel target for RC.

\section{Introduction}

The incidence of renal cancer ranks eighth among all malignant diseases worldwide (1), while its mortality rate ranks sixth (2). Clear cell carcinoma is the dominant pathological type of renal cancer (1). Early renal carcinoma (RC) has atypical clinical symptoms and signs, which are easily overlooked. This, coupled with the lack of specific tumor markers, makes early diagnosis of RC remarkably difficult (3). Furthermore, it is easy for RC to progress into a late stage, since transfer or invasion of real cancer cells into the surrounding organs occurs at an early stage, as the kidney does not have a serous layer and is located adjacent to the trachea, aorta and other important organs. Clinically, $>1 / 2$ of patients with $\mathrm{RC}$ had missed the opportunity to remove the tumor at diagnosis, which is a challenge for the clinicians (3). At present, the treatment of RC that has been widely used is the combined strategy of surgical excision, radiotherapy and chemotherapy, but its efficiency is still unsatisfactory, since the 5-year survival rate following surgery is only $20-40 \%(4,5)$.

Apoptosis is not only a normal cell cycle process, but it is also vital for homeostasis, since it can remove excessive damaged and aging mutant cells (6). Apoptosis disorders are involved in the pathogenesis of a variety of malignant tumors, and are considered to be the key reason for the occurrence and development of tumors, being closely associated with tumor drug resistance (3). Inhibition of apoptosis leads to the accumulation of mutations in the cell, which initiates differentiation (7). Malignant cells do not die if insufficient apoptosis occurs (8).

The members of the family of inhibitor of apoptosis proteins (IAPs), which contains eight members, are the key regulators of cytokinesis, apoptosis and signal transduction, and have been demonstrated to be closely associated with 
oncogenesis (9). Apollon, namely baculoviral IAP repeat containing 6 (BIRC6), is a membrane-associated protein that localizes to the Golgi compartment and the vesicular system, and is the largest member of the IAP family (9). It inhibits apoptosis by binding to cysteine aspartate-specific proteases (caspases) directly. Its anti-apoptotic function is much stronger than that of the proteins of the B-cell lymphoma-2 family, mainly through the function of Smac, high temperature requirement A protein serine peptidase 2 and caspase $(10,11)$. Increasing evidence has shown that upregulation of Apollon may be important in tumor generation (12-16). However, the association between RC and Apollon is unclear.

In the present study, Apollon expression was detected by immunohistochemistry, western blotting and reverse transcription-quantitative polymerase chain reaction (RT-qPCR) in RC tissues, adjacent non-cancerous tissues and normal tissues respectively, in order to analyze the association between Apollon expression and the clinicopathological features of RC, and to highlight the link between Apollon expression and the occurrence, development and prognosis of RC.

\section{Materials and methods}

Patients and specimens. The patients enrolled in the present study were recruited from the Third Affiliated Hospital of Southern Medical University (Guangzhou, China) from February 2010 till February 2014. The patients were diagnosed as $\mathrm{RC}$ by $>2$ pathologists. Specimens, including 50 cases of cancer tissue, 42 cases of adjacent non-cancerous tissue and 30 cases of paired normal tissue, were obtained by intraoperative radical renalectomy. The patients included 48 males and 2 females, who were $<75$ years old. All patients were first-diagnosed cases, without chemotherapy, radiotherapy or other treatments prior to being sampled, and their clinical and pathological data were complete and reliable. The present study was approved by the Third Affiliated Hospital of Southern Medical University. The usage of information and the collection of specimens was conducted once informed consent from the patients or their families was obtained.

Reagents and equipment. Anti-Apollon antibody was purchased from Abcam (Cambridge, UK) (ab84429). The PowerVision two-step immunohistochemistry kit was purchased from Beijing Zhongshan Golden Bridge Biotechnology Co., Ltd. (Beijing, China) (PV-6001). TRIzol, for total RNA extraction, was purchased from Invitrogen (Thermo Fisher Scientific, Inc., Waltham, MA, USA) (15596-026). The RT kit was purchased from Promega Corporation (Madison, WI, USA) (A5001). The RT-qPCR kit was purchased from Promega Corporation (A6001). Paraffin-embedding equipment, paraffin-slicing equipment and the automatic upright microscope system (DM5000 B) were purchased from Leica Microsystems GmbH (Wetzlar, Germany). The 400W ultraviolet imaging system was purchased from Kodak (Rochester, NY, USA). The PCR equipment (ABI PRISM 7500 Sequence Detection System) was purchased from Applied Biosystems (Thermo Fisher Scientific, Inc.). The Total Protein Extraction kit, polyvinylidene difluoride membranes and Beyo-ECL Plus Detection System were purchased from Beyotime Institute of Biotechnology (Haimen, China).
Table I. Expression of Apollon in tumor, adjacent and normal epithelial tissues.

\begin{tabular}{lrrr}
\hline $\begin{array}{l}\text { Apollon } \\
\text { expression }\end{array}$ & $\begin{array}{c}\text { Cancer } \\
\text { tissue }\end{array}$ & $\begin{array}{c}\text { Adjacent } \\
\text { tissue }\end{array}$ & $\begin{array}{c}\text { Normal } \\
\text { tissue }\end{array}$ \\
\hline Total, N & 50 & 42 & 30 \\
- & 8 & 28 & 20 \\
+ & 6 & 6 & 7 \\
++ & 8 & 6 & 3 \\
+++ & 28 & 2 & 0 \\
P-value & 0.002 & 0.012 & 0.010 \\
\hline
\end{tabular}


Figure 1. Cytoplasmic Apollon expression was detected in RC tissues with different tumor differentiation degree: (A) Well-differentiated, (B) moderately differentiated and (C) poorly differentiated. (D) No expression of Apollon was detected in the cytoplasm of carcinoma cells in RC tissues, whereas rare cytoplasmic Apollon expression was detected in normal epithelium. (E) Apollon-positive tissues. Apollon expression was mainly observed in clear cells or underlying basal cells. (F) Apollon expression was negative in normal epithelium. Original magnification, x200. RC, renal carcinoma.

Immunohistochemistry. The rapid PowerVision two-step staining method was used with the following specifications: Paraffin slices were obtained with a thickness of $5 \mu \mathrm{m}$, which were next incubated at $65^{\circ} \mathrm{C}$ for $60 \mathrm{~min}$, followed by dewaxing, hydration and high-temperature antigen retrieval in a microwave by incubation in a $0.1 \mathrm{M}$ citrate solution ( $\mathrm{pH}$ 6.0) for $10 \mathrm{~min}$. Next, the slides were incubated with $3 \% \mathrm{H}_{2} \mathrm{O}_{2}$ at room temperature for $20 \mathrm{~min}$, followed by incubation with goat serum (ab7481; Abcam) at room temperature for $20 \mathrm{~min}$ and incubation with anti-Apollon antibody (1:400; ab19609; Abcam) at $4^{\circ} \mathrm{C}$ overnight. The slides were heated up the following day prior to being incubated with an anti-rabbit antibody at room temperature for $20 \mathrm{~min}$. Subsequently, the slides were subjected to 3,3'-diaminobenzidine and hematoxylin staining, prior to being mounted for light microscopic examination. Immunohistochemical staining was scored independently by two pathologists without knowledge of the patients' characteristics. Any discrepancy was solved by consensus review. The score of immunoreactivity was performed by calculating the extent and intensity of positive staining of cells in a 
A
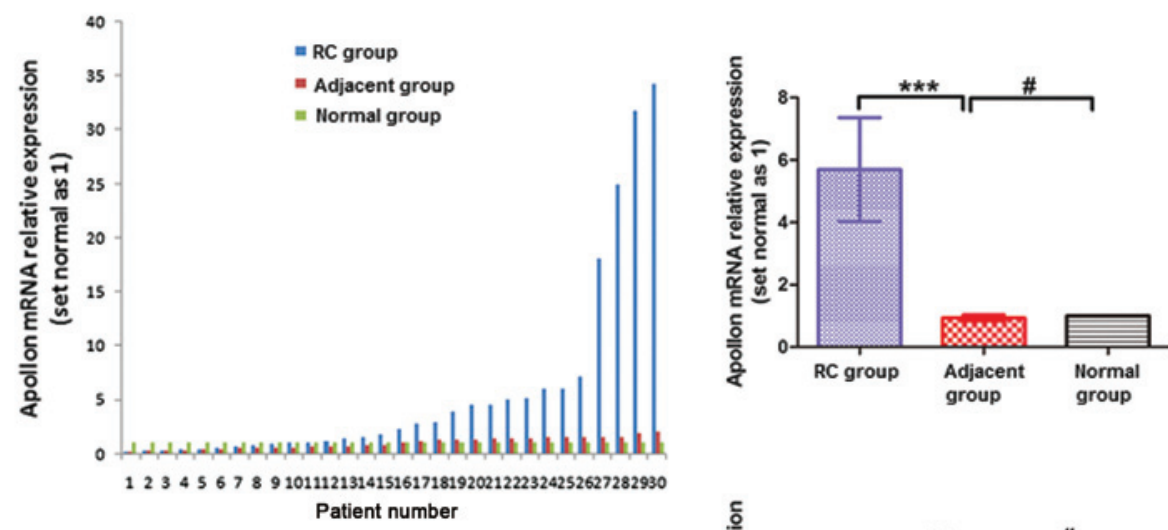

B
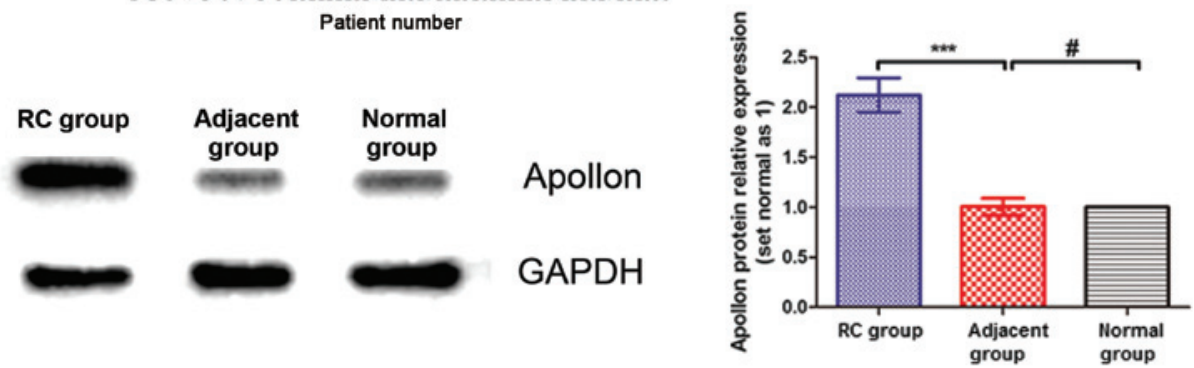

Figure 2. (A) Relative fold-change in Apollon mRNA expression in all RC specimens and adjacent non-cancerous tissues. Normal tissue was set as 1 . The difference in Apollon mRNA expression between the three groups is significant. ${ }^{* * *} \mathrm{P}<0.001$, comparison between the RC group and the adjacent group; ${ }^{\text {"}} \mathrm{P}=0.436$, comparison between the adjacent group and the normal group. (B) Representative western blot analysis of Apollon protein expression in RC, adjacent non-cancerous tissue and normal tissue. ${ }^{* * *} \mathrm{P}<0.05$, comparison between the $\mathrm{RC}$ group and the adjacent group; ${ }^{*} \mathrm{P}=0.706$, comparison between the adjacent group and the normal group. Apollon expression in cancer is relatively high $(\mathrm{P}<0.05)$. RC, renal carcinoma; mRNA, messenger RNA.

semi-quantitative manner. Score interpretation was performed as described previously (17). The standards for evaluation included the following: Positive staining intensity ( 0 , negative; 1 , weak positive; 2 , moderate positive; and 3 , strong positive) and proportion of positive areas $(0,0 \% ; 1,1-30 \% ; 2,30-70 \%$; and $4,70-100 \%$ ). The final score was obtained by multiplication of the aforementioned two scores, with 0 regarded as negative, 1-2 regarded as weak positive, 3-4 regarded as moderate positive and $\geq 5$ regarded as strong positive. The negative and weak-moderate positive results were considered as low expression of Apollon, while the strong positive results were considered as Apollon overexpression. RC patients were divided into a low-expression group or a high-expression group, based on their final score, which was considered as high expression if its value was $>5$.

Western blotting. Tissues were lysed with the Total Protein Extraction kit (Beyotime Institute of Biotechnology), and the protein lysates were resolved on $12 \%$ SDS-PAGE prior to being transferred to polyvinylidene difluoride membranes (IPFL00010; EMD Millipore, Billerica, MA, USA). The membranes were blocked with 5\% milk and then incubated for $2 \mathrm{~h}$ with primary antibodies against Apollon (ab19609; Abcam) and GAPDH (ab8245; Abcam) at $37^{\circ} \mathrm{C}$. The membranes were washed with PBS containing Tween 20 and then incubated with the secondary antibody (ab131366; Abcam). The Beyo-ECL Plus Detection System (Beyotime Institute of Biotechnology) was employed to visualize the bands. The Apollon protein expression levels were quantified by Image Lab Software 5.1 (Bio-Rad Laboratories, Inc., Hercules, CA, USA) and represented as the densitometric ratio of the targeted protein to GAPDH.
$R T$ - $q P C R$. Total RNA was extracted from $1 \mathrm{mg}$ renal tissue using TRIzol (Invitrogen (Thermo Fisher Scientific, Inc.), according to the manufacturer's protocol. Upon treatment with DNA-free DNase (Ambion; Thermo Fisher Scientific, Inc.) to remove the chromosomal DNA, complementary (c)DNA was synthesized using an RT kit (Promega Corporation) and stored at $-20^{\circ} \mathrm{C}$ until use. The messenger RNA (mRNA) expression levels of Apollon and $\beta$-actin were determined by RT-qPCR using the ABI PRISM 7500 Sequence Detection System. The primer sequences (sense/anti-sense) were: Apollon, 5'-TGA CAGGGCATACATCACAG-3'/5'-GCAACAATCTCCCAC TGAAG-3' and $\beta$-actin, 5'-GCACCACACCTTCTACAA TGAG-3'/5'-GATAGCACAGCCTGGATAGCA-3'. The mRNA expression levels of the target genes were normalized to the $\beta$-actin signal, which served as a housekeeping gene. All the reactions were performed in triplicate using $20-\mu 1$ samples containing $50 \mathrm{ng}$ cDNA. The reaction protocol involved heating for $10 \mathrm{~min}$ at $95^{\circ} \mathrm{C}$, followed by 40 cycles of amplification $\left(15 \mathrm{sec}\right.$ at $95^{\circ} \mathrm{C}$ and $1 \mathrm{~min}$ at $\left.60^{\circ} \mathrm{C}\right)$. The data were analyzed using the ABI PRISM 7500 Sequence Detection software version 1.2 (Applied Biosystems; Thermo Fisher Scientific, Inc.). The levels of Apollon expression in unknown samples were calculated as a ratio of Apollon to $\beta$-actin. Determinations were performed three times for each sample.

Statistical analysis. The patients were categorized into two groups according to their level of Apollon expression (high Apollon expression group and low Apollon expression group). The differences in Apollon expression with respect to the clinical factors at diagnosis, including gender, age, alcohol consumption history, tumor size, histological grade, T-stage, $\mathrm{N}$-stage and tumor-node-metastasis (TNM)-stage, were 
Table II. Associations between Apollon expression and clinicopathological characteristics of renal cancer patients.

\begin{tabular}{|c|c|c|c|c|}
\hline \multirow[b]{2}{*}{ Characteristics } & \multirow[b]{2}{*}{$\mathrm{N}$} & \multicolumn{2}{|c|}{ Apollon } & \multirow[b]{2}{*}{ P-value } \\
\hline & & High expression & Low expression & \\
\hline Gender & & & & 0.201 \\
\hline Male & 48 & 26 & 22 & \\
\hline Female & 2 & 2 & 0 & \\
\hline Age, years & & & & 0.212 \\
\hline$\geq 55$ & 34 & 17 & 17 & \\
\hline$<55$ & 16 & 11 & 5 & \\
\hline $\begin{array}{l}\text { Alcohol consumption } \\
\text { history ( } \geq 10 \text { years) }\end{array}$ & & & & 0.976 \\
\hline Yes & 41 & 23 & 18 & \\
\hline No & 9 & 5 & 4 & \\
\hline Tumor size, cm & & & & 0.749 \\
\hline$\geq 4$ & 26 & 14 & 12 & \\
\hline$<4$ & 24 & 14 & 10 & \\
\hline Histological grade & & & & 0.156 \\
\hline Well & 16 & 6 & 10 & \\
\hline Moderate & 26 & 16 & 10 & \\
\hline Poor & 8 & 6 & 2 & \\
\hline T-stage & & & & 0.006 \\
\hline $\mathrm{T} 1$ & 11 & 3 & 8 & \\
\hline $\mathrm{T} 2$ & 16 & 6 & 10 & \\
\hline $\mathrm{T} 3$ & 18 & 15 & 3 & \\
\hline $\mathrm{T} 4$ & 5 & 4 & 1 & \\
\hline $\mathrm{N}$-stage & & & & 0.007 \\
\hline N0 & 17 & 5 & 12 & \\
\hline $\mathrm{N} 1+\mathrm{N} 2+\mathrm{N} 3$ & 37 & 23 & 10 & \\
\hline TNM-stage & & & & 0.035 \\
\hline I & 4 & 2 & 2 & \\
\hline II & 20 & 7 & 13 & \\
\hline III & 26 & 19 & 7 & \\
\hline
\end{tabular}

TNM, tumor-node-metastasis.

analyzed. The expression levels are presented as median values. The quantitative data were compared using one-way analysis of variance and unpaired $t$ test, while the qualitative data were compared using Pearson's $\chi^{2}$ test. Statistical analyses were conduced with SPSS 19.0 (SPSS, Inc., Chicago, IL, USA). $\mathrm{P}<0.05$ was considered to indicate a statistically significant difference.

\section{Results}

Patients. In total, 50 patients (males, 48; females, 2) were enrolled in the study. Their mean age was 58.6 years (range, 42-74 years). According to the 7th edition of the International Union Against Cancer's renal cancer staging manual (2009 edition), the enrolled patients were classified as follows: 4 cases of stage I, 20 cases of stage II and 26 cases of stage III (12).
Increased Apollon protein and mRNA expression in RC tissues Immunohistochemical staining. Apollon protein was detected by immunohistochemical staining (Fig. 1). Apollon protein was expressed in RC tissues, adjacent non-cancerous tissues and normal renal tissues. Apollon expression was detected mainly in the cytoplasm of the carcinoma cells and in the cytoplasm of the clear cell carcinoma cells or underlying basal cells of the adjacent or normal tissues.

The positive reactants of Apollon were yellow or brown substances that mainly existed in the cytoplasm (Fig. 1). According to the aforementioned standards, the expression rate of Apollon was 56\% (28/50) in the tumor tissue, while it was 5\% (2/42) in the adjacent non-cancerous tissue and $0 \%$ $(0 / 30)$ in the normal renal mucosa epithelial tissue. This difference was statistically significant $(\mathrm{P}<0.001)$ (Table I).

RT- $q P C R$ and western blotting. The mRNA expression of Apollon in each group was normalized against the endogenous 


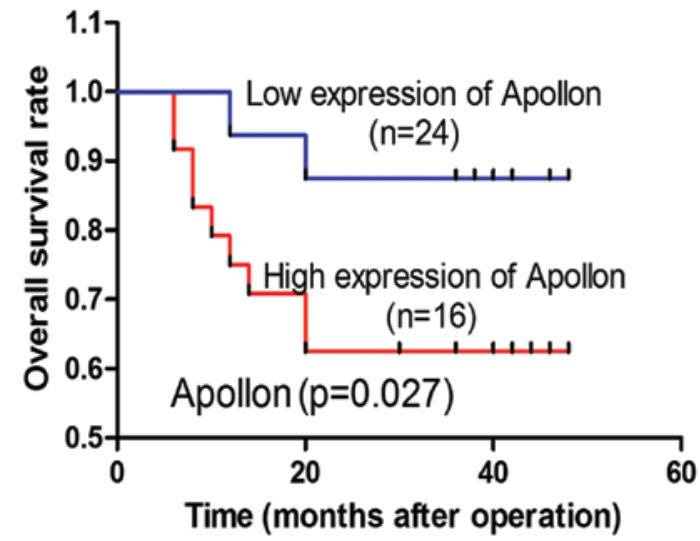

Figure 3. Prognostic significance was assessed using Kaplan-Meier survival estimates and log-rank tests. The overall survival of patients with high Apollon expression was significantly shorter than that of patients with low Apollon expression.

mRNA expression of the housekeeping gene $\beta$-actin. The relative expression of Apollon mRNA was described as $2^{-\Delta \Delta C q}$ (18). Apollon expression in RC tissues was significantly higher than that in adjacent non-cancerous tissues and normal renal tissues $(\mathrm{P}=0.012)$ (Fig. 2A). Western blotting analysis also revealed that Apollon protein expression in RC tissues was significantly higher than that in adjacent non-cancerous tissues and normal tissues (Fig. 2B).

Apollon expression and clinicopathological variables. The association between Apollon high expression (score $\geq 5$ ) and various clinicopathological features was analyzed as aforementioned (Table II). There was no correlation between Apollon overexpression and age $(\mathrm{P}=0.823)$, gender $(\mathrm{P}=0.201)$, histological grade $(\mathrm{P}=0.156)$, tumor size $(\mathrm{P}=0.749)$ or alcohol consumption history $(\mathrm{P}=0.976)$. Significant associations were observed between Apollon overexpression and nodal involvement $(\mathrm{P}=0.007)$, T-stage $(\mathrm{P}=0.006)$ and TNM-stage $(\mathrm{P}=0.035)$ (Table II).

Survival analysis. In total, $80 \%$ (40 of 50) of the patients were followed up successfully (the remaining 10 patients could not be contacted). To evaluate the effect of Apollon expression on survival, Kaplan-Meier analysis and log-rank test were used. The results indicated that high level of Apollon expression was correlated with short overall survival (OS) $(\mathrm{P}=0.017)$ (Fig. 3).

Univariate analysis revealed that Apollon expression, T-stage, TNM-stage and tumor size were associated with OS, while tumor differentiation, age or alcohol consumption history had no prognostic significance for OS (Table III).

\section{Discussion}

Apollon is the largest member of the IAP family (19), and it was identified by Chen et al in 1999 (19). The Apollon gene locates on 2p21-22, and encodes a markedly large protein $(530 \mathrm{kDa})$ that contains a single BIR domain and an ubiquitin-conjugating enzyme domain. Apollon is abundant in brain, placenta, testis, lymphatic cells and secretory organs (19). Different studies have reported that Apollon is a dual regulator of cell proliferation and cell death, with multiple functions due to its
Table III. Cox proportional hazards regression model was used in univariate analysis.

\begin{tabular}{lcc}
\hline Characteristics & $\begin{array}{c}\text { Hazard ratio } \\
(95 \% \mathrm{CI})\end{array}$ & P-value \\
\hline $\begin{array}{l}\text { T-stage } \\
\text { (T1 vs. T2 vs. T3 vs. T4) }\end{array}$ & $\begin{array}{c}(0.612-1.768) \\
2.458\end{array}$ & 0.883 \\
$\begin{array}{l}\text { TNM-stage } \\
\text { (III vs. I and II) }\end{array}$ & $\begin{array}{c}(1.229-4.917) \\
1.106\end{array}$ & 0.011 \\
$\begin{array}{l}\text { Tumor size } \\
(\geq 4 \text { cm vs. }<4 \text { cm) }\end{array}$ & $\begin{array}{c}0.702-1.744) \\
0.855\end{array}$ & 0.663 \\
$\begin{array}{l}\text { Apollon expression } \\
\text { (positive vs. negative) }\end{array}$ & $(0.758-0.953)$ & 0.005 \\
\hline
\end{tabular}

TNM, tumor-node-metastasis; CI, confidence interval.

different functional domains and diverse binding patterns (9). Apollon has been reported to serve a significant role in apoptosis resistance in a variety of cancers $(10,19-23)$, including breast cancers, colon cancers, gliomas, fibrosarcomas, osteosarcomas, lung cancers, cervical cancers and prostate cancers. However, a role for Apollon in renal cancer has rarely been reported. In the present study, Apollon was observed to also serve a role in apoptosis resistance in RC. These results are in agreement with those of Zhang et al (24). This process may facilitate further studies on RC.

Regarding the expression of IAPs in RC, previous studies revealed a significant overexpression of IAPs in cancer tissues and normal squamous epithelia, including cellular (c)IAP-1, cIAP-2, XIAP and survivin. However, the expression of these proteins was an early event in renal cancer, and did not correlate with the histological type of cancer or stage of the tumors (25-27). The potential roles of IAP family proteins in the homeostasis of normal tissues as well as in the pathogenesis of RC are still unknown, since studies on Apollon and RC are limited. In the present study, the differences in Apollon expression were compared in a variety of malignant renal tissues and adjacent non-cancerous tissues and benign renal tissues. Immunohistochemical staining revealed a markedly high frequency of Apollon expression in the majority of cancer cells. By contrast, in normal mucosa, the presence of positive cells was partial, and in certain cases, the signals were negative (Fig. 1). Thus, differences in the positive cell ratio would result in differences in intensity of mRNA expression for Apollon, indicating that Apollon could have a significant role in renal cancer.

According to our immunohistochemistry data, Apollon protein was detected in the majority of cancer samples (42 of 50, 84\%). The protein was located in the cytoplasm, which confirmed a previous study that reported that Apollon localized to the Golgi compartment and the vesicular system (28). The expression of Apollon was observed in numerous cases of normal squamous epithelial tissue, mainly in the basal layer (28). The expression of Apollon is ubiquitous in fetal tissues, but becomes restricted during development, and appears to be negligible in the majority of terminally differentiated adult tissues, which confirms its role 
in caryomitosis (29). From the clinical data, the present study noticed that the expression of Apollon was not associated with age, gender, tumor size or tumor differentiation, but exhibited a strong association with TNM-stage, T-staging and nodal involvement. These results indicated that high expression of Apollon leads to increased malignant biological characteristics, regardless of the degree of tumor differentiation, which is inconsistent with previous studies (29-33) reporting that Apollon expression indicates poor differentiation. By contrast, similar results to the ones reported in the present study were reported by Low et al (23), who studied the association between prostate cancer and Apollon. The results of that study indicated that increased expression of Apollon was a late event in prostate cancer and did not correlate with Gleason grade (23). Our data suggested that Apollon is functionally an indicator of metastasis or prognosis in renal cancer.

The increase in Apollon expression in renal cancer suggests an important role for this protein in the development and progression of the disease. In view of the pro-survival function of Apollon in RC cells and other systems (12-14,20), a cytoprotective advantage to $\mathrm{RC}$ cells is expected to be provided by elevated expression of Apollon, thus promoting $\mathrm{RC}$ development and progression. Numerous previous studies have demonstrated that the expression level of Apollon was significantly associated with patients' reaction to therapy, recurrence, OS, disease-free survival (DFS) and prognosis (29-33). A previous multivariate analysis revealed that Apollon was an independent prognostic factor for OS and DFS in human epithelial ovarian cancer (29), which is in agreement with our results. In addition, various in vitro studies have demonstrated that Apollon overexpression indicates a stronger resistance to chemotherapy, since silencing its expression can sensitize cancer cells to chemotherapy, which can be interpreted by the cytoprotective advantage of Apollon and the chemotherapeutic mechanism (20,21,30-32). However, the role of Apollon in renal cancer remains uncertain. The present study demonstrated that Apollon may be a therapeutic target and a potential predictor of prognosis in RC. Future studies are required to expand the therapeutic arsenal in the fight against renal cancer and to improve the quality of life of RC patients.

In conclusion, the present study indicates for the first time that Apollon expression is associated with the biological characteristics of renal cancer, and it is potentially a valuable predictor and novel target for renal cancers. Although the mechanisms of Apollon function in tumorigenesis and metastasis are still unclear, the present study provides evidence for further studies in vitro and in vivo to clarify the regulatory mechanisms of IAP expression in renal cancer in association with the apoptotic signaling pathways.

\section{References}

1. Kamangar F, Dores GM and Anderson WF: Patterns of cancer incidence, mortality, and prevalence across five continents: Defining priorities to reduce cancer disparities in different geographic regions of the world. J Clin Oncol 24: 2137-2150, 2006.

2. Parkin DM, Bray F, Ferlay J and Pisani P: Global cancer statistics 2002. CA Cancer J Clin 55: 74-108, 2005.

3. Naito M: Molecular mechanism of apoptosis inhibition by IAPs and its implication to cancer therapy. Seikagaku 78: 525-528, 2006 (In Japanese).
4. Mariette C, Piessen G and Triboulet JP: Therapeutic strategies in oesophageal carcinoma: Role of surgery and other modalities. Lancet Oncol 8: 545-553, 2007.

5. Lerut T, Coosemans W, Decker G, De Leyn P, Nafteux P and Van Raemdonck D: Cancer of the esophagus and gastro-esophageal junction: Potentially curative therapies. Surg Oncol 10: 113-122, 2001.

6. Giancotti FG and Tarone G: Positional control of cell fate through joint integrin/receptor protein kinase signaling. Annu Rev Cell Dev Biol 19: 173-206, 2003.

7. Evan G: Cancer-a matter of life and cell death. Int J Cancer 71: 709-711, 1997.

8. Wong RS: Apoptosis in cancer: From pathogenesis to treatment. J Exp Clin Cancer Res 30: 87, 2011.

9. Hauser HP, Bardroff M, Pyrowolakis G and Jentsch S: A giant ubiquitin-conjugating enzyme related to IAP apoptosis inhibitors. J Cell Biol 141: 1415-1422, 1998.

10. Qiu XB and Goldberg AL: The membrane-associated inhibitor of apoptosis protein, BRUCE/Apollon, antagonizes both the precursor and mature forms of Smac and caspase-9. J Biol Chem 280: 174-182, 2005.

11. Qiu XB, Markant SL, Yuan J and Goldberg AL: Nrdp1-mediated degradation of the gigantic IAP, BRUCE, is a novel pathway for triggering apoptosis. EMBO J 23: 800-810, 2004.

12. Pohl $\mathrm{C}$ and Jentsch S: Final stages of cytokinesis and midbody ring formation are controlled by BRUCE. Cell 132: 832-845, 2008.

13. Ren J, Shi M, Liu R, Yang QH, Johnson T, Skarnes WC and Du C: The Birc6 (Bruce) gene regulates p53 and the mitochondrial pathway of apoptosis and is essential for mouse embryonic development. Proc Natl Acad Sci USA 102: 565-570, 2005.

14. Chu L, Gu J, Sun L, Qian Q, Qian C and Liu X: Oncolytic adenovirus-mediated shRNA against Apollon inhibits tumor cell growth and enhances antitumor effect of 5-fluorouracil. Gene Ther 15: 484-494, 2008.

15. Lopergolo A, Pennati M, Gandellini P, Orlotti NI, Poma P, Daidone MG, Folini M and Zaffaroni N: Apollon gene silencing induces apoptosis in breast cancer cells through p53 stabilisation and caspase-3 activation. Br J Cancer 100: 739-746, 2009.

16. Van Houdt WJ, Emmink BL, Pham TV, Piersma SR, Verheem A, Vries RG, Fratantoni SA, Pronk A, Clevers H, Borel Rinkes IH, et al: Comparative proteomics of colon cancer stem cells and differentiated tumor cells identifies BIRC6 as a potential therapeutic target. Mol Cell Proteomics 10: M111.011353, 2011.

17. Chen Y, Fu D, Xi J, Ji Z, Liu T, Ma Y, Zhao Y, Dong L, Wang Q and Shen X: Expression and clinical significance of UCH37 in human renal carcinoma. Dig Dis Sci 57: 2310-7, 2012.

18. Livak KJ and Schmittgen TD: Analysis of relative gene expression data using real-time quantitative PCR and the 2(-Delta Delta C(T)) method. Methods 25: 402-408, 2001.

19. Chen Z, Naito M, Hori S, Mashima T, Yamori T and Tsuruo T: A human IAP-family gene, apollon, expressed in human brain cancer cells. Biochem Biophys Res Commun 264: 847-854, 1999.

20. Hao Y, Sekine K, Kawabata A, Nakamura H, Ishioka T, Ohata H, Katayama R, Hashimoto C, Zhang X, Noda T, et al: Apollon ubiquitinates SMAC and caspase-9, and has an essential cytoprotection function. Nat Cell Biol 6: 849-860, 2004.

21. Lamers F, Schild L, Koster J, Speleman F, Øra I, Westerhout EM, van Sluis P, Versteeg R, Caron HN and Molenaar JJ: Identification of BIRC6 as a novel intervention target for neuroblastoma therapy. BMC Cancer 12: 285, 2012.

22. Bianchini M, Levy E, Zucchini C, Pinski V, Macagno C, De Sanctis P, Valvassori L, Carinci P and Mordoh J: Comparative study of gene expression by cDNA microarray in human colorectal cancer tissues and normal mucosa. Int J Oncol 29: 83-94, 2006.

23. Low CG, Luk IS, Lin D, Fazli L, Yang K, Xu Y, Gleave M, Gout PW and Wang Y: BIRC6 protein, an inhibitor of apoptosis: Role in survival of human prostate cancer cells. PLoS One 8: e55837, 2013.

24. Zhang S, Tang W, Weng S, Liu X, Rao B, Gu J, Chen S, Wang Q, Shen X, Xue R and Dong L: Apollon modulates chemosensitivity in human renal carcinoma. Oncotarget 5: 7183-7197, 2014.

25. Nemoto T, Kitagawa M, Hasegawa M, Ikeda S, Akashi T, Takizawa T, Hirokawa K and Koike M: Expression of IAP family proteins in esophageal cancer. Exp Mol Pathol 76: 253-259, 2004.

26. Zhou S, Ye W, Shao Q, Qi Y, Zhang M and Liang J: Prognostic significance of XIAP and NF- $\kappa$ B expression in esophageal carcinoma with postoperative radiotherapy. World J Surg Oncol 11: 288, 2013 
27. Vaishlia NA, Zinov'eva MV, Sass AV, Kopantsev EP, Vinogradova TV and Sverdlov ED: Increase of BIRC5 gene expression in non-small cell lung cancer and renal carcinoma does not correlate with expression of genes SMAC/DIABLO and PML encoding its inhibitors. Mol Biol (Mosk) 42: 652-661, 2008 (In Russian).

28. Bartke T, Pohl C, Pyrowolakis G and Jentsch S: Dual role of BRUCE as an antiapoptotic IAP and a chimeric E2/E3 ubiquitin ligase. Mol Cell 14: 801-811, 2004.

29. Wang L, Chen YJ, Hou J, Wang YY, Tang WQ, Shen XZ and Tu RQ Expression and clinical significance of BIRC6 in human epithelial ovarian cancer. Tumour Biol 35: 4891-4896, 2014.

30. Sung KW, Choi J, Hwang YK, Lee SJ, Kim HJ, Lee SH, Yoo KH, Jung HL and Koo HH: Overexpression of Apollon, an antiapoptotic protein, is associated with poor prognosis in childhood de novo acute myeloid leukemia. Clin Cancer Res 13: 5109-5114, 2007.
31. Ismail EA, Mahmoud HM, Tawfik LM, Habashy DM, Adly AA, El-Sherif NH and Abdelwahab MA: BIRC6/Apollon gene expression in childhood acute leukemia: Impact on therapeutic response and prognosis. Eur J Haematol 88: 118-127, 2012.

32. Tang W, Xue R, Weng S, Wu J, Fang Y, Wang Y, Ji L, Hu T, Liu T, Huang X, et al: BIRC6 promotes hepatocellular carcinogenesis: Interaction of BIRC6 with p53 facilitating p53 degradation. Int J Cancer 136: E475-E487, 2015.

33. Dong X, Lin D, Low C, Vucic EA, English JC, Yee J, Murray N, Lam WL, Ling V, Lam S, et al: Elevated expression of BIRC6 protein in non-small-cell lung cancers is associated with cancer recurrence and chemoresistance. J Thorac Oncol 8: 161-170, 2013. 